Quim. Nova, Vol. 28, No. 6, 1030-1037, 2005

\title{
TIOSSEMICARBAZONAS: MÉTODOS DE OBTENÇÃO, APLICAÇÕES SINTÉTICAS E IMPORTÂNCIA BIOLÓGICA
}

\author{
Rômulo P. Tenório e Alexandre J. S. Góes* \\ Departamento de Antibióticos, Universidade Federal de Pernambuco, Cidade Universitária, 50670-901 Recife - PE \\ José G. de Lima, Antônio R. de Faria, Antônio J. Alves e Thiago M. de Aquino \\ Departamento de Ciências Farmacêuticas, Universidade Federal de Pernambuco, Cidade Universitária, 50470-521 Recife - PE
}

Recebido em 4/8/04; aceito em 2/3/05; publicado na web em 2/8/05

\begin{abstract}
THIOSEMICARBAZONES: PREPARATION METHODS, SYNTHETIC APPLICATIONS AND BIOLOGICAL IMPORTANCE. Thiosemicarbazones are a class of compounds known by their chemical and biological properties, such as antitumor, antibacterial, antiviral and antiprotozoal activity. Their ability to form chelates with metals has great importance in their biological activities. Their synthesis is very simple, versatile and clean, usually giving high yields. They are largely employed as intermediates, in the synthesis of others compounds. This article is a survey of some of these characteristics showing their great importance to organic and medicinal chemistry.
\end{abstract}

Keywords: thiosemicarbazone; preparation methods; synthetic applications.

\section{INTRODUÇÃO}

A enzima ribonucleotídeo redutase (RR) vem sendo relacionada como um alvo promissor na terapia do câncer ${ }^{1,2}$ e doenças protozoárias $^{3}$. Esta enzima existe em todas as células vivas e apresenta a função de catalisar o passo limitante na síntese dos deoxiribonucleotídeos necessários para síntese do DNA ${ }^{4}$. É constituída por duas sub-unidades, conhecidas como $\mathrm{R}_{1}$ e $\mathrm{R}_{2}$. A sub-unidade $R_{2}$ contém um radical livre tirosila, que é estabilizada por um centro de ferro não-heme. Ambos, o ferro e o grupo tirosila, são essenciais para a atividade catalítica ${ }^{5}$.

Os inibidores desta enzima são extremamente efetivos em bloquear a biossíntese de DNA, por conta dos baixos níveis intracelulares dos deoxiribonucleotídeos ${ }^{6}$. A gentamicina e a hidroxiuréia são os únicos inibidores desta enzima aprovados pela "Food and Drug Administration (FDA)", sendo que a hidroxiuréia atua na subunidade $\mathrm{R}_{2}$ da enzima ${ }^{1,7}$.

A hidroxiuréia, entretanto, é pouco efetiva uma vez que possui pouca afinidade pela RR e um curto tempo de meia-vida no plas$\mathrm{ma}^{8}$. Dentre outras substâncias conhecidas por também apresentarem atividade inibitória sobre esta enzima, estão a 3-aminopiridina2-carboxaldeído tiossemicarbazona (triapina - 3-AP) e a 3aminopiridina-4-metil-2-carboxaldeído tiossemicarbazona (3AMP) $)^{9}$. Segundo Liu et al. ${ }^{9}$, essas substâncias são 1000 vezes mais potentes que a hidroxiuréia para inibir a ribonucleotídeo redutase em células da leucemia L-1210. Estudos indicam que a atividade inibitória destas substâncias sobre a RR é devida ao complexo formado entre elas e o átomo de ferro presente no sítio catalítico da $\mathrm{RR}^{10}$. Atualmente, a triapina está sendo avaliada em testes clínicos de fase II como possível fármaco antitumoral ${ }^{11}$. Estas duas substâncias fazem parte da classe das tiossemicarbazonas.

As tiossemicarbazonas são compostos de considerável interesse científico, devido as suas importantes propriedades químicas e biológicas, tais como antitumoral ${ }^{11}$, antibacteriana ${ }^{12}$, antiviral ${ }^{13}$, antiprotozoária $^{14}$, citotóxica ${ }^{15}$, dentre outras. A estrutura química das

*e-mail: ajsg@ufpe.br

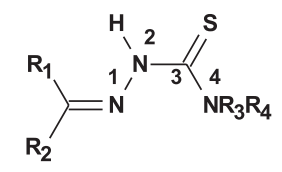

$$
R_{1}, R_{2}, R_{3} \text { e } R_{4}=H \text {, Alquil e aril }
$$

Figura 1. Numeração das tiossemicarbazonas

tiossemicarbazonas e a numeração dos seus átomos segundo a IUPAC $^{16}$ é mostrada na Figura 1.

Estes compostos são geralmente obtidos pela reação de condensação quimiosseletiva de tiossemicarbazidas com aldeídos e/ou cetonas, e recebem a denominação da classe tiossemicarbazona após o nome do respectivo aldeído ou cetona condensado ${ }^{17,18}$. São conhecidos, também, pelas suas excelentes propriedades para formarem complexos organometálicos, comportando-se como agentes quelantes ${ }^{17,19}$.

Do ponto de vista sintético, apresentam como característica principal sua versatilidade de obtenção, assim como sua vasta aplicação como intermediários de muitos núcleos importantes. Em geral, estas moléculas apresentam baixo custo de síntese, além de grande economia de átomos, uma vez que, com exceção da água que é liberada na sua síntese, todos os outros átomos dos compostos reagentes estarão presentes na molécula final ${ }^{20}$.

\section{CONSIDERAÇÕES MOLECULARES E ELETRÔNICAS}

Segundo Casas e colaboradores ${ }^{17}$, as tiossemicarbazonas não substituídas na posição N-4 apresentam estrutura básica, C=N-NHCS-NH ${ }_{2}$, aproximadamente planar, com o átomo de enxofre em posição anti em relação ao átomo de nitrogênio da função imina (1, Figura 2). Fatores eletrônicos e estéricos contribuem para este arranjo estrutural, porém, possivelmente o fator mais importante é que o átomo de enxofre em posição anti possibilita a ocorrência de ligação de hidrogênio intramolecular entre o nitrogênio da imina e os hidrogênios da tioamida ${ }^{21}$. Por outro lado, este arranjo estrutural muda significativamente se forem adicionados grupos substituintes na po- 
sição N-4, favorecendo a conformação sin entre o átomo de nitrogênio da imina e o átomo de enxofre (2, Figura 2) ${ }^{21}$.

As tiossemicarbazonas apresentam-se como sistemas com extrema deslocalização eletrônica, principalmente quando há grupos aromáticos ligados ao carbono da imina. Esta afirmação está baseada nos trabalhos pioneiros de Palenik e colaboradores ${ }^{22}$. A Figura $2 b$ mostra, esquematicamente, a influência nos comprimentos de ligação devido à deslocalização dos elétrons $\pi$ nas tiossemicarbazonas.

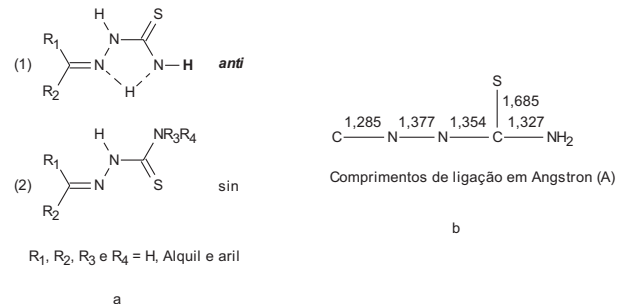

Figura 2. Arranjo estrutural e comprimentos de ligação de tiossemicarbazonas

Pode-se observar que o fragmento N-C-N apresenta um comprimento de ligação muito próximo ao observado para as duplas ligações $(C=C, 1,201-1,246 \AA)^{23}$, enquanto que na ligação $C-S$ $(1,685 \AA)$ ocorre exatamente o inverso, indicando que o átomo de enxofre permite um maior envolvimento das duas ligações $\mathrm{C}-\mathrm{N}$ na deslocalização dos elétrons $\pi^{17}$.

O caráter parcialmente duplo da ligação $\mathrm{C}-\mathrm{N}$ pode também ser facilmente evidenciado pela técnica de espectrometria de ressonância magnética nuclear de hidrogênio $\left(\mathrm{RMN}{ }^{1} \mathrm{H}\right)$, uma vez que os hidrogênios em $\mathrm{NH}_{2}$ aparecem como dois sinais não equivalentes. Isto acontece devido à rotação restrita da ligação $\mathrm{C}-\mathrm{NH}_{2}$ por conta da dupla ligação parcial que, desta forma, torna os hidrogênios diastereotópicos ${ }^{24,25}$. A temperaturas elevadas $(\sim 323 \mathrm{~K})$ estes sinais coalescem como mostra o trabalho de Ferrari e colaboradores ${ }^{26}$.

Devido a esta deslocalização eletrônica, as tiossemicarbazonas podem coexistir na forma tiona ou tiol em equilíbrio tautomérico (Esquema 1).

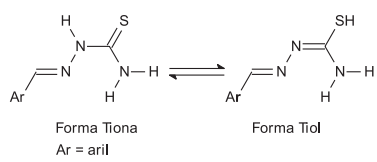

Esquema 1. Formas tautoméricas das tiossemicarbazonas

O espectro de infravermelho (IV) mostra a forma predominante deste tautomerismo, uma vez que o aparecimento de uma banda forte na região de $1028-1082 \mathrm{~cm}^{-1}$ indica a presença da tiocarbonila $(\mathrm{C}=\mathrm{S})$. Contudo, a ausência desta banda e o aparecimento de outra na região de $2500-2600 \mathrm{~cm}^{-1}$ demonstra que a forma tiol é mais predominante ${ }^{27,28}$. Vale ressaltar que o baixo valor da banda de estiramento de $\mathrm{C}=\mathrm{S}$ é devido ao seu acentuado caráter de ligação simples, e que esta pode variar de acordo com o ambiente quími$\mathrm{co}^{29-32}$.

Obviamente, complexos metálicos de tiossemicarbazonas mudam consideravelmente a posição destas bandas, principalmente aquelas que estão envolvidas na ligação coordenada ${ }^{253}$. Bharti e colaboradore ${ }^{27}$ obtiveram complexos de paládio e observaram deslocamentos negativos $\left(14-39 \mathrm{~cm}^{-1}\right)$ para a banda de $\mathrm{C}=\mathrm{N}$, que aparece normalmente entre $1556-1630 \mathrm{~cm}^{-1}$, indicando o envolvimento da função azometina na ligação coordenada, assim como para a tiocarbonila $(\mathrm{C}=\mathrm{S})$, onde as bandas foram deslocadas para frequiências menores $\left(13-35 \mathrm{~cm}^{-1}\right)$.

\section{OBTENÇÃO DE TIOSSEMICARBAZONAS}

A preparação de tiossemicarbazonas é extensamente explorada e descrita na literatura ${ }^{6,24,34-36}$. Na análise retrossintética, em geral, duas estratégias podem ser empregadas: obtenção direta, pela reação quimiosseletiva de aldeídos e/ou cetonas com as tiossemicarbazidas, e obtenção indireta, através da preparação prévia das tiossemicarbazidas, utilizando hidrazina $\left(\mathrm{NH}_{2}-\mathrm{NH}_{2}\right)$ e diferentes reagentes, seguida de condensação com o derivado carbonilado específico (Esquema 2).

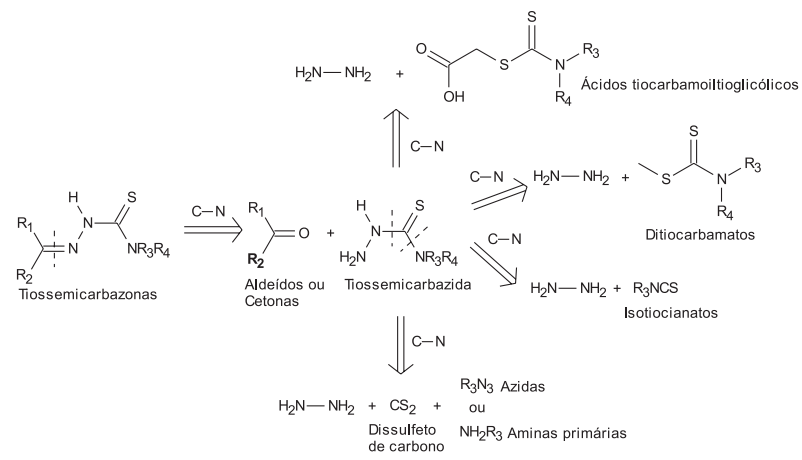

Esquema 2. Análise retrossintética de tiossemicarbazonas

Obtenção direta das tiossemicarbazonas a partir de tiossemicarbazidas

As tiossemicarbazidas podem ser adquiridas comercialmente. A síntese é descrita pela condensação equimolar de um derivado carbonilado, do tipo aldeído ou cetona, com tiossemicarbazidas em meio alcoólico sob refluxo e quantidades catalíticas de ácido ${ }^{35,37-39}$. Esta reação é bastante conhecida por sua alta quimiosseletividade, versatilidade e rapi$\mathrm{dez}$, apresentando geralmente altos rendimentos ${ }^{18,40,41}$.

O mecanismo reacional é semelhante ao de formação de iminas. Inicia-se com a protonação do oxigênio da carbonila para formar o intermediário íon oxônio, seguida de ataque nucleofílico do nitrogênio N-1 da tiossemicarbazida para formar o intermediário hemiaminal protonado. Este perde uma molécula de água e, após neutralização, forma-se a tiossemicarbazona ${ }^{42,43}$ (Esquema 3).

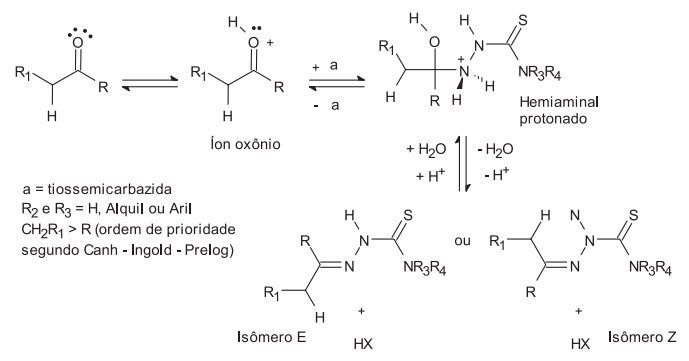

Esquema 3. Mecanismo de formação de tiossemicarbazonas

Apesar da reação ser favorável à formação das tiossemicarbazonas, é fácil notar o caráter reversível de todas as etapas de sua síntese, daí a importância da utilização da catálise ácida em $\mathrm{pH}$ controlado. Em geral, a formação da tiossemicarbazona é mais rápida em $\mathrm{pH}$ entre 4 e 5 . Em valores de $\mathrm{pH}$ menores que 4, há possibilidade de ocorrer protonação do nitrogênio N-1 da tiossemicarbazida e, conseqüentemente, a velocidade de condensação será mais lenta. Por outro lado, em $\mathrm{pH}>5$, a velocidade de reação também diminui, visto que a carbonila se encontrará progressivamente menos protonada ${ }^{42,43}$. 
Vários derivados de tiossemicarbazona foram obtidos utilizando-se as condições reacionais descritas acima. Karah ${ }^{15}$, trabalhando com derivados de isatina, reagiu estes com a tiossemicarbazida e obteve tiossemicarbazonas em rendimentos muito altos, alguns variando de 97 a 99\% (Esquema 4a). Neste trabalho, a síntese foi realizada em solução etanólica, sob refluxo, contendo quantidades catalíticas de ácido sulfúrico concentrado. Em outro estudo, Benbrook e colaboradores ${ }^{40}$ sintetizaram tiossemicarbazonas derivadas de heteroarotinóides, um conhecido sistema molecular derivado de retinóides ${ }^{44}$, utilizando ácido acético como catalisador. Aqui, a condensação da tiossemicarbazida com o aldeído correspondente também forneceu facilmente a molécula alvo em rendimentos satisfatórios de $83 \%$.

Alguns autores, efetuaram uma pequena modificação neste método e observaram que as tiossemicarbazonas também poderiam ser sintetizadas em solução neutra indicando que, possivelmente, o emprego do ácido não seria uma condição indispensável para formação dessas moléculas ${ }^{34,45,46}$.

Neste sentido, Chiyanzu e colaboradores ${ }^{46}$ demonstraram que as tiossemicarbazonas derivadas de isatina, que tinham sido anteriormente obtidas por Karah ${ }^{15}$ utilizando o método convencional, também eram facilmente sintetizadas sem o auxílio de catalisadores (Esquema 4b).

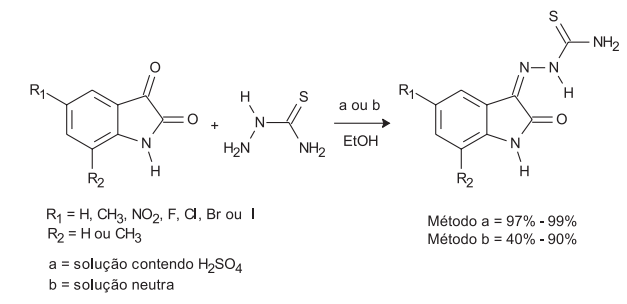

Esquema 4. Obtenção de tiossemicarbazonas pelo método convencional (a) e em solução neutra (b)

As tiossemicarbazonas são geralmente obtidas como misturas de isômeros $E$ e Z no estado sólido ${ }^{47}$. Em solução, há isomerização da configuração $Z$ para $E$, devido a sua maior estabilidade termodinâmica ${ }^{48}$. Utilizando técnicas de espectroscopia Raman e RMN ${ }^{1} \mathrm{H}$, Temperini e colaboradores ${ }^{49}$ mostraram a predominância do isômero $E$ da 2-formil-piridina tiossemicarbazona em DMSO e em meio aquoso.

A isomerização é extremamente influenciada pela presença de ácido e pela natureza dos grupos substituintes ligados ao carbono azometina, bem como pelos substituintes ligados ao nitrogênio da tioamida $(\mathrm{N}-4)$.

Karabatsos e colaboradore $\mathrm{s}^{50}$ mostraram, em estudos utilizando a técnica de $\mathrm{RMN}{ }^{1} \mathrm{H}$, que os hidrogênios azometina de tiossemicarbazonas na configuração $E$ ressonam a campo magnético baixo em relação a tiossemicarbazonas em configuração $Z$, mesmo em diferentes solventes. Resultado semelhante foi obtido por Antonini e colaboradores ${ }^{28}$, alguns anos depois.

Como regra geral, as tiossemicarbazonas derivadas de aldeídos tendem a formar preferencialmente o isômero $E$, termodinamicamente mais estável, enquanto que nas derivadas de cetonas assimétricas a proporção entre $E$ e $Z$ depende da estrutura dos substituintes ligados à carbonila ${ }^{42}$.

Obtenção indireta das tiossemicarbazonas pela preparação prévia de tiossemicarbazidas, utilizando hidrato de hidrazina como material de partida

Conforme mencionado, as tiossemicarbazonas são obtidas atra- vés de reação entre compostos carbonilados e tiossemicarbazidas comercialmente obtidas ou previamente preparadas. A seguir, são descritos alguns métodos de obtenção de tiossemicarbazidas a partir de hidrato de hidrazina.

\section{Reação com ácido tiocarbamoiltioglicólico}

Este método fornece uma rota bem interessante quando se pretende obter tiossemicarbazidas substituídas na posição N-4 com grupos incomuns, não encontrados comercialmente. A reação ocorre em meio alcalino, sob refluxo, contendo ácido tiocarbamoiltioglicólico e hidrato de hidrazina. Estes reagem para formar a tiossemicarbazida, liberando o ácido tioglicólico ${ }^{14}$ (Esquema 5, Equação 1). Os ácidos tiocarbamoiltioglicólicos, por sua vez, podem ser obtidos segundo metodologia desenvolvida por O'Sullivan e colaboradores ${ }^{51}$.

\section{Reação com ditiocarbamatos}

O método que usa ditiocarbamatos e hidrato de hidrazina é, de forma geral, bem semelhante ao descrito anteriormente. Neste caso, a obtenção das tiossemicarbazidas ocorre após adição nucleofílica da hidrazina ao carbono da tiocarbonila, com conseqüente remoção do grupo $\mathrm{S}_{-} \mathrm{CH}_{3}$ (Esquema 5, Equação 2) ${ }^{52}$.

$\mathrm{O}$ derivado ditiocarbamato de metila pode ser obtido a partir de aminas primárias ou secundárias, em reação com dissulfeto de carbono e uma base forte em meio alcoólico fazendo-se, em seguida, a reação de $S$-metilação com iodeto de metila ${ }^{52,53}$.

Uma modificação na metodologia descrita acima é comumente utilizada na síntese de tiossemicarbazonas. Ao invés de fazer uso dos ditiocarbamatos, utiliza-se hidrazinacarboditiolato de metila e aminas primárias ou secundárias ${ }^{54,55}$. Esta modificação apresenta uma vantagem, uma vez que a estrutura básica da tiossemicarbazona já estará formada após a remoção do grupo $\mathrm{S}_{-} \mathrm{CH}_{3}$ (Esquema 5, Equação 3).

Como esperado, quanto mais nucleofílica for a amina utilizada mais rápida será a formação da tiossemicarbazona ${ }^{55}$.

\section{Reação com isotiocianatos}

O hidrato de hidrazina reage com isotiocianatos para formar tiossemicarbazidas $^{56-58}$. Esta reação geralmente apresenta rendimentos entre 70 e $90 \%$ (Esquema 5, Equação 4).

Este método também apresenta uma modificação semelhante ao que foi observado com os ditiocarbamatos. Utilizando-se hidrazonas como nucleófilos, no lugar de hidrato de hidrazina, tem-se a formação direta das tiossemicarbazonas (Esquema 5, Equação 5) ${ }^{59,60}$.

\section{Reação com dissulfeto de carbono}

A reação de derivados de amina com dissulfeto de carbono, seguida da adição de hidrato de hidrazina é um método muito útil na preparação de tiossemicarbazidas. Pandeya e colaboradores ${ }^{61}$ utilizaram esta metodologia para sintetizar, em uma única etapa, a tiossemicarbazida a partir de 2-amino-4-( $p$-cloro-fenil)-tiazol (Esquema 5, Equação 6).

Outra forma de obtenção de tiossemicarbazidas utilizando dissulfeto de carbono é através do método de Tsuge e colaboradores $^{52}$. Neste método, tiossemicarbazidas são sintetizadas a partir de azidas. Estas são tratadas inicialmente com trifenilfosfina e dissulfeto de carbono para fornecer os isotiocianatos correspondentes e, em seguida, faz-se a adição da hidrazina (Esquema 5, Equação 7). 


$$
\overbrace{\mathrm{OH}}^{\text {Refluxo }} \underset{\substack{\mathrm{R}_{2} \mathrm{~N}^{\prime} \\ \text { Rend. não fornecido }}}{\stackrel{\text { Soluçäo }}{\text { Alcalina }}}
$$<smiles>CSC(=S)NCc1ccc([N+](=O)[O-])cc1</smiles>

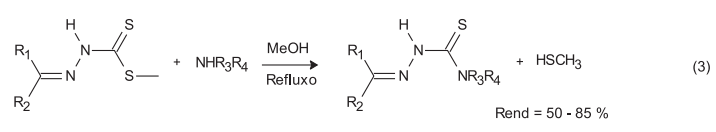$$
\text { (4) }
$$
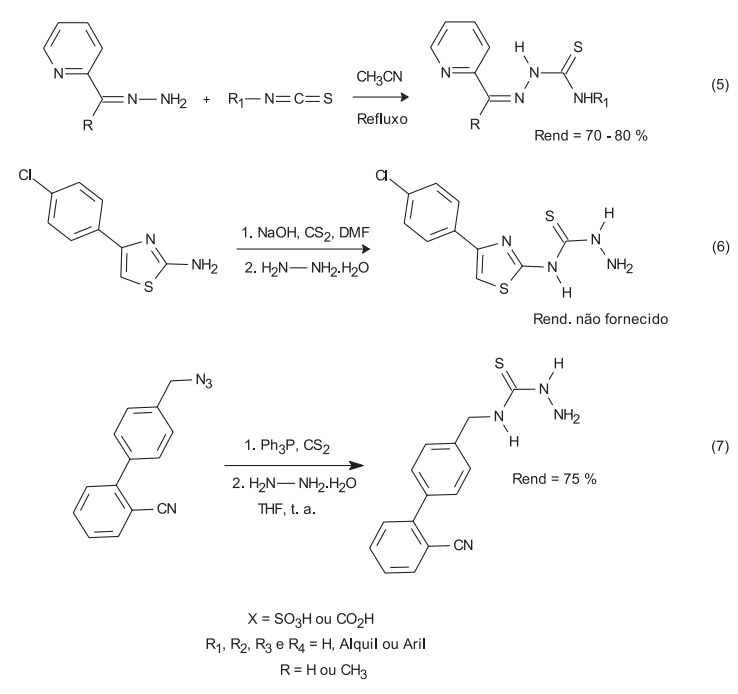

(7)

Esquema 5. Métodos de obtenção de tiossemicarbazidas e tiossemicarbazonas

\section{APLICAÇÕES SINTÉTICAS DE TIOSSEMICARBAZONAS}

As tiossemicarbazonas são substâncias muito empregadas como intermediários na síntese orgânica de importantes heterociclos. Sua vasta aplicação deve-se, entre outros fatores, a sua já mencionada versatilidade de obtenção e manipulação, em detrimento de outras substâncias que exigem alto grau de cuidado. São substâncias de fácil estocagem, não necessitando de armazenagem especial, nem tampouco são sensíveis à luz. Devido à natureza quimiosseletiva de sua formação, podem ser empregadas em diversas situações.

\section{Obtenção de tiazol}

Os tiazóis e seus derivados são importantes heterociclos e estão relacionados com um grande número de aplicações biológicas. Dentre estas, podem-se citar atividades antimicrobiana, antifúngica e antinflamatória ${ }^{35}$.

As tiossemicarbazonas, em presença de compostos do tipo $\alpha$ halogeno-cetonas, funcionam muito bem na síntese de tiazóis. Isto acontece porque as $\alpha$-halogeno-cetonas são muito reativas frente ao grupo tioamida nucleofílico presente na estrutura das tiossemicarbazonas e, conseqüentemente, levam às ciclização para formar o heterociclo. Sarodnick e colaboradores ${ }^{37}$ sintetizaram derivados tiazóis empregando tiossemicarbazonas e 3-bromopiruvato de etila em etanol sob refluxo (Esquema 6, Equação 1).

\section{Obtenção de 1,3,4-tiadiazol}

Tiossemicarbazonas também podem ser utilizadas na obtenção de 1,3,4-tiadiazóis ${ }^{62,63}$. Chauvière e colaboradores ${ }^{62}$ sintetizaram $^{2}$ 5-nitroimidazol-1,3,4-tiadiazol, utilizando reação de ciclização oxidativa com íons férricos e tiossemicarbazona (Esquema 6, Equação 2).

Outro método de obtenção de 1,3,4-tiadiazóis a partir de tiossemicarbazonas é através da ciclização destas em presença de anidrido acético ou haletos de acila, seguida de oxidação com permanganato de potássio ou cloreto de ferro(III) ${ }^{63}$.

A formação destes derivados por este método pode ser explicada pelo mecanismo proposto por Kubota e colaboradores ${ }^{63}$, onde primeiramente formar-se-ia um intermediário com os dois átomos de nitrogênio, presentes nos grupos azometina e tioamida, das tiossemicarbazonas $\mathrm{N}$-acilados. Este sofreria um rearranjo favorecendo a ciclização e formação do anel 1,3,4-tiadiazol após oxidação (esquema 6, Equação 3).

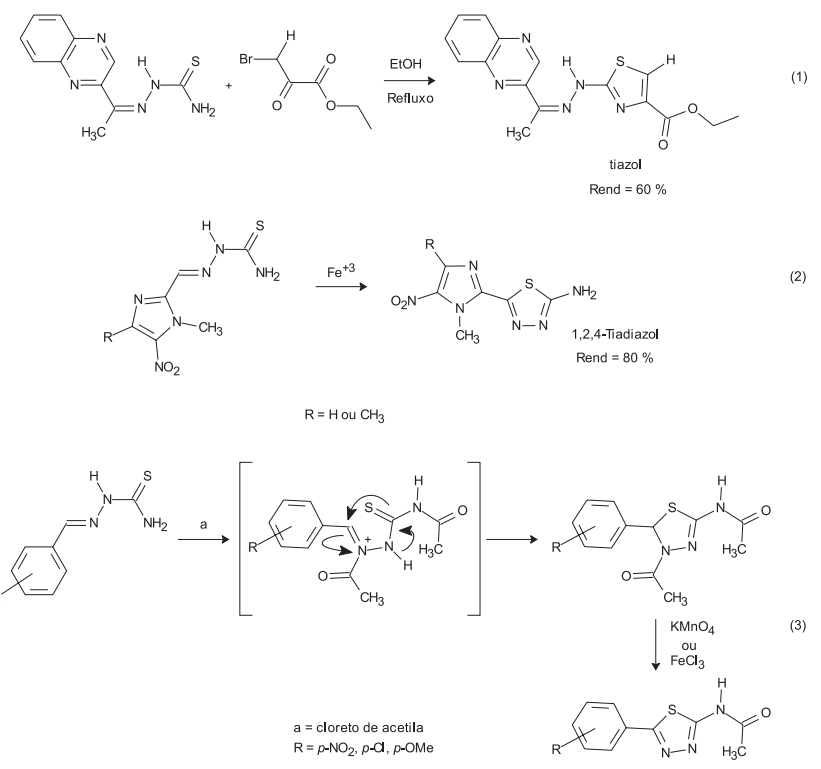

Esquema 6. Obtenção de tiazol; 1,3,4-tiadiazol; e mecanismo de formação 2-acetamido-1,3,4-tiadiazol, a partir de tiossemicarbazonas

\section{Obtenção de 1,2,4-triazina}

1,2,4-triazinas podem ser obtidas, como demonstraram Ivanchtchenko e colaboradores ${ }^{64}$, utilizando-se tiossemicarbazonas derivadas de isatinas. Nesta síntese, o anel triazina é formado pela ciclização da tiossemicarbazona quando esta é tratada com hidróxido de sódio aquoso sob refluxo (Esquema 7, Equação 1).

Bobek, Glowka e Parthasarathy ${ }^{65}$ obtiveram 1,2,4-triazina utilizando um método um pouco diferente. A tiossemicarbazona foi primeiramente tratada com iodeto de metila para, em seguida, ser ciclizada com bicarbonato de sódio em meio aquoso. Pode-se observar que o grupo $S$-metil foi estrategicamente colocado para funcionar na etapa seguinte como grupo de saída frente ao metóxido de sódio (Esquema 7, Equação 2).

\section{Obtenção de 1,2,4-ditiazolidinas}

As tiossemicarbazonas também são empregadas na síntese de 1,2,4-ditiazolidinas ${ }^{66-68}$. All e colaboradores ${ }^{67}$ obtiveram derivados ditiazolidinas em três etapas a partir de tiossemicarbazonas, utilizando reações de debenzilação oxidativa como etapa chave. Pri- 
<smiles>Cc1cc(Br)cc2c1NC(=O)C2=NN(N)C(=S)Nc1ccc(Br)cc1</smiles>

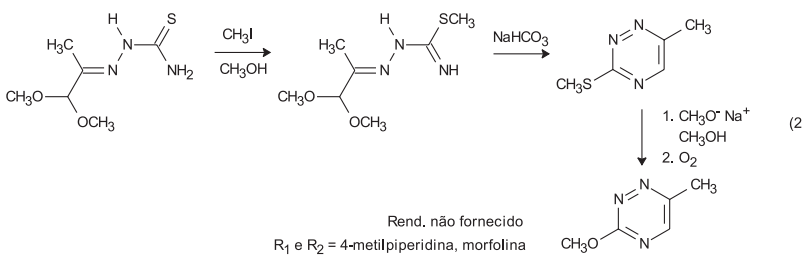

Esquema 7. Preparação de 1,2,4-triazina

meiramente, as tiossemicarbazonas foram benziladas e, em segui$\mathrm{da}$, tratadas com derivados arilisotiocianatos. O composto formado foi então oxidado com bromo em clorofórmio para fornecer a ditiazolidina esperada (Esquema 8, Equação 1).

\section{Obtenção de 4-tiazolidinonas}

As 4-tiazolidinonas são derivados carbonilados das tiazolidinas. Sua estrutura química apresenta-se formada por um anel de cinco membros, contendo dois heteroátomos, um enxofre e um nitrogênio, e um grupo carbonila na posição $4^{69}$. Estes compostos são muito importantes na química medicinal devido às suas atividades biológicas, tais como antimicrobiana ${ }^{57}$, antiprotozoária ${ }^{70}$, fungicida ${ }^{71}$, antituberculose ${ }^{72}$, entre outras.

As 4-tiazolidinonas podem ser sintetizadas a partir de tiossemicarbazonas como demonstraram Reeve e Barron ${ }^{73}$. Nesse trabalho, as tiazolidinonas foram obtidas da reação entre tiossemicarbazonas e fenil (triclorometil) carbinol, como único produto reacional, com rendimentos variando entre 31 a $79 \%$ (Esquema 8, Equação 2).

Há evidências que o mecanismo reacional nesta síntese envolva a formação inicial de um intermediário epóxido do derivado carbinol, seguida de ataque nucleofílico do ânion tioenolato ao carbono $\alpha$ do epóxido. Isto levaria à formação de um intermediário cloreto de ácido que, finalmente, ciclizaria para formar a tiazolidinona ${ }^{73}$.

Outra forma de obter 4-tiazolidinonas substituídas na posição 5, a partir de tiossemicarbazonas, é através da reação destas com anidrido maléico ${ }^{69,74}$ (Esquema 8, Equação 3).

A utilização de compostos $\alpha$-bromo ou $\alpha$-cloro carbonilados também é muito empregada nas reações de ciclização objetivando a síntese de 4-tiazolidinonas ${ }^{57,72,75}$.

\section{Obtenção de 5-aminopirazol}

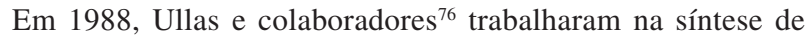
tiossemicarbazonas, visando sua aplicação na obtenção de análogos nucleosídeos do tipo adenina. As tiossemicarbazonas foram utilizadas com o propósito de preparar, com bons rendimentos, o intermediário 5-aminopirazol, que seria utilizado como material de partida na síntese de vários análogos do aciclovir (fármaco empregado no tratamento de Herpes tipo-2).

A tiossemicarbazona utilizada na síntese para formar o núcleo 5-aminopirazol foi obtida a partir da 2-formilpropionitrila. A síntese iniciou-se com o tratamento da tiossemicarbazona com etóxido de sódio em solução etanólica, onde, após a formação do composto 2-(tiocarbamoil)-3-aminopirazol, fez-se a hidrólise com hidróxido de sódio em meio metanólico (Esquema 8, Equação 4).

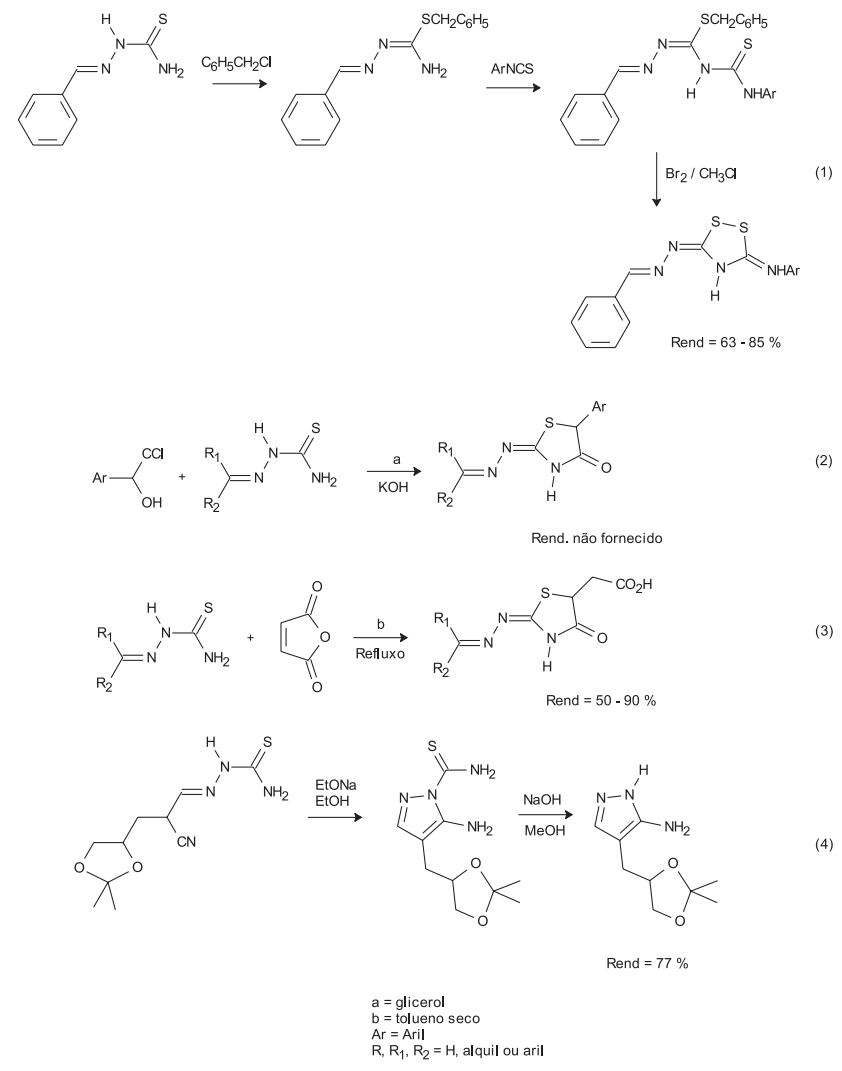

Esquema 8. Aplicação de tiossemicarbazonas na obtenção de ditiazolidinas, 4-tiazolidinonas e 5-aminopirazol

\section{CONSIDERAÇÕES BIOLÓGICAS DE TIOSSEMICARBAZONAS E DE ALGUNS DE SEUS COMPLEXOS METÁLICOS ${ }^{77}$}

Como mencionado anteriormente, as tiossemicarbazonas pertencem a uma classe de substâncias bastante conhecidas por suas aplicações importantes na pesquisa de novos fármacos, em função de seu largo espectro de ação ${ }^{78}$. Alguns autores atribuem esta propriedade à alta afinidade que as tiossemicarbazonas apresentam pela enzima ribonucleotídeo redutase, responsável pelo passo crucial na síntese do DNA e, conseqüentemente, da divisão celular ${ }^{1,2}$. Outros consideram que suas propriedades biológicas são devidas à capacidade que apresentam de formar complexos com cátions metálicos, formando quelatos ${ }^{27}$. Por outro lado, Greenbaum e colaboradores ${ }^{79}$ sugeriram que o mecanismo de ação das tiossemicarbazonas é ainda complexo e deve acontecer através da inibição de múltiplos alvos.

Neste sentido, as tiossemicarbazonas apresentam-se como ligantes versáteis tanto na forma neutra quanto na forma aniônica, podendo formar ligação coordenada com metais através do átomo de enxofre e do átomo de nitrogênio azometina $(\mathrm{C}=\mathrm{N})^{27,34}$. Esta capacidade de formar ligação coordenada é aumentada se houver grupos doadores de elétrons ligados ao carbono da função azometina ${ }^{17}$. A seguir, são descritas as atividades biológicas de algumas tiossemicarbazonas de potencial valor biológico e de alguns complexos metálicos importantes.

\section{Atividade antiprotozoária}

Diversos tipos de protozoários foram estudados quanto as suas suscetibilidades às tiossemicarbazonas, como relatam trabalhos publicados recentemente ${ }^{14,80,81}$.

Bharti e colaboradores ${ }^{14}$ efetuaram testes antiprotozoários de 
alguns derivados tiossemicarbazonas e obtiveram bons resultados biológicos frente à Entamoeba histolytica e Trichomonas vaginalis, utilizando metronidazol como fármaco de referência. A substância 5-nitro-tiofeno-2-carbaldeído- $N(4)$-hexametilimina tiossemicarbazona (5-NT-HMINTSC) apresentou em concentrações de $1,71 \mu \mathrm{M}$, inibição de $50 \%$ de crescimento $\left(\mathrm{CI}_{50}\right)$ de Entamoeba histolytica, em comparação com $2,10 \mu \mathrm{M}$ de metronidazol necessários para igual inibição (Figura 3a). Outro derivado, 5-nitrotiofeno-2-carbaldeído- $N$ (4)-butil tiossemicarbazona (5-NTBuTSC) apresentou uma $\mathrm{CI}_{50}$ de $1,49 \mu \mathrm{M}$ em atividade tricomonicida, em comparação com o valor de metronidazol necessário $(1,92 \mu \mathrm{M})$ para o mesmo efeito (Figura 3a).

Também foi relatada atividade antimalárica para algumas tiossemicarbazonas. Klayman e colaboradores ${ }^{82}$ observaram que os grupos tiocarbonila e azometina eram necessários para esta atividade biológica. Outros resultados mostram que as propriedades das tiossemicarbazonas de formar quelatos com os cátions metálicos são responsáveis pelas atividades antiprotozoárias ${ }^{27,80}$. Outras atividades, como antitripanossoma ${ }^{20,83}$ e leishmanicida ${ }^{84}$, foram também relatadas.

Bharti e colaboradores ${ }^{27}$ também relataram a atividade antiamoebicida de tiossemicarbazonas complexadas com Pd(II) e constataram que seus complexos eram mais ativos contra este protozoário que as tiossemicarbazonas livres.

\section{Atividade antiviral}

Atividade inibitória sobre a enzima transcriptase reversa (RT), presente em vírus do tipo HIV, foi reportada para tiossemicarbazonas, derivadas de piridoxal, complexadas com estanho(IV) (Figura 3b). Segundo Casas et al. ${ }^{85}$, a complexação de tiossemicarbazonas em geral causa um aumento da atividade biológica quando comparada ao ligante livre.

Atividade anti HIV também foi relatada para tiossemicarbazonas por Teitz e colaboradores ${ }^{13}$. Foram estudadas duas tiossemicarbazonas: $N$-metilisatina-4':4'-dietiltiossemicarbazona (MIBDET) e $N$-alilisatina-4' $4^{\prime}$-dialiltiossemicarbazona (A-IBDAT). Ambas demonstraram atuar sobre a síntese de proteínas estruturais do HIV.

Genova e colaboradores ${ }^{86}$, por outro lado, compararam a atividade inibitória da benzil bis (tiossemicarbazona) e seu respectivo complexo metálico de paládio(II) sobre linhagens de vírus do tipo HSV 1 e 2 (herpes simples 1 e 2) e observaram que o complexo metálico exibe melhora significativa na atividade antiviral em comparação com a tiossemicarbazona livre (Figura 3c).

\section{Atividade antitumoral}

Liu e colaboradores ${ }^{9}$ e Niu e colaboradores ${ }^{87}$ demonstraram a grande potencialidade da substância 3-aminopiridina-2-carboxaldeído tiossemicarbazona (triapina - 3-AP) como uma das principais substâncias orgânicas no combate a tipos específicos de células tumorais, tais como carcinoma de fígado M-109, carcinoma de ovário humano A2780 e em ratos apresentando leucemia L1210.

Tiossemicarbazonas derivadas de $\alpha-(\mathrm{N})$-heterociclos carboxaldeído apresentam a propriedade de formar complexos fortes com metais de transição, como ferro e cobre. Estudos indicam que a triapina atua inativando a atividade da ribonucleotídeo redutase, através do complexo organometálico formado com o átomo de ferro inibindo, desta forma, a etapa limitante da síntese de DNA ${ }^{5,33,87}$.

Li e colaboradores ${ }^{7}$ desenvolveram um pró-fármaco desta tiossemicarbazona, pela inclusão do grupamento bezoil fosfato, com objetivo de melhorar as propriedades farmacocinéticas e, também, sua utilidade terapêutica frente a células tumorais M-109 (Figura 3d). Segundo os autores, a bioativação do pró-fármaco ocorreria após uma quebra na ligação fósforo - oxigênio, mediada por uma fosfatase alcalina, levando a um intermediário que passaria por uma série de fragmentações para formar, finalmente, a 3aminopiridina-2-carboxaldeído tiossemicarbazona ${ }^{7}$.

Estudos pré-clínicos de fase I da triapina indicaram resultados promissores em pacientes em estágio avançado de câncer utilizando doses variando de $5 \mathrm{mg} / \mathrm{m}^{2}$ a $105 \mathrm{mg} / \mathrm{m}^{2}$, incluindo atividade sobre tumores resistentes à hidroxiuréia, sem o aparecimento de toxicidade significativa ${ }^{11}$. Atualmente, esta substância encontra-se em ensaios clínicos de fase II $^{77,79}$.

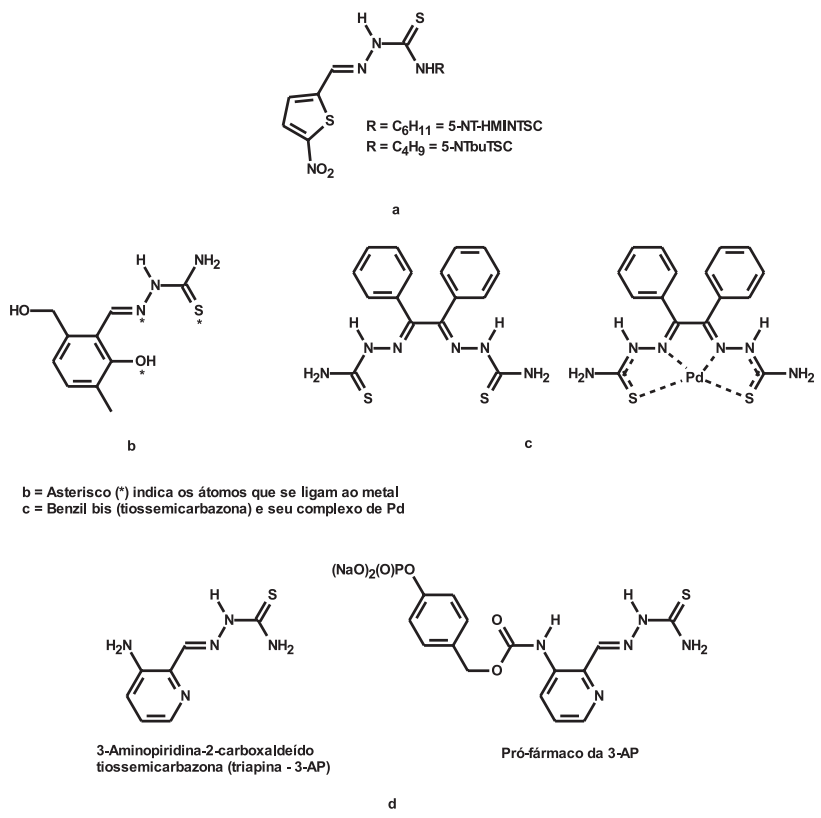

Figura 3. Estruturas de algumas tiossemicarbazonas de importância biológica

\section{CONCLUSÃO}

As tiossemicarbazonas fazem parte de uma classe de moléculas altamente versáteis quanto à sua obtenção e aplicação. Devido à sua natureza quimiosseletiva, as tiossemicarbazidas e os compostos carbonilados formam rapidamente as tiossemicarbazonas que, geralmente, apresentam elevados rendimentos. Seu emprego na síntese de importantes heterociclos é conhecido por utilizarem reações simples e apresentarem alta estabilidade em diferentes condições reacionais.

Quanto a seu potencial biológico, diversos trabalhos mostram a eficácia destas moléculas como potentes inibidores da síntese do DNA. Esta propriedade confere às tiossemicarbazonas a possibilidade de serem aplicadas na busca por novas substâncias terapêuticas em diversos campos de pesquisa. Dentre estas, as atividades antitumorais e antiprotozoárias aparecem, sem dúvida, como as mais relevantes, devido aos importantes resultados encontrados na pesquisa acadêmica e industrial.

\section{AGRADECIMENTOS}

Ao CNPq e à Capes, pelo apoio financeiro e pela bolsa de mestrado concedida e a todos aqueles que contribuíram para o desenvolvimento deste trabalho. 


\section{REFERÊNCIAS}

1. Louie, A. Y.; Meade, T. J.; Chem. Rev. 1999, 99, 2711.

2. Cory, J. G.; Adv. Enzyme Regul. 1988, 27, 437.

3. Melo, E. J. T.; Mayerhoffer, R. O.; Souza, W.; FEMS Microbiol. Lett. 2000, $185,79$.

4. Finch, R. A.; Liu, M. C.; Grill, S. P.; Rose, W. C.; Loomis, R.; Vasquez, K. M.; Cheng, Y. C.; Sartorelli, A. C.; Biochem. Pharmacol. 2000, 59, 983.

5. Finch, R. A.; Liu, M. C.; Cory, A. H.; Cory, J. G.; Sartorelli, A. C.; Adv. Enzyme Regul. 1999, 39, 12.

6. Li, J.; Chen, S.; Li, X.; Niu, C.; Doyle, T. W.; Tetrahedron 1998, 54, 393.

7. Li, J.; Luo, X.; Wang, Q.; Zheng, L.; King, I.; Doyle, T. W.; Chen, S.; Bioorg. Med. Chem. Lett. 1998, 8, 3159 .

8. Gwilt, P. R.; Tracewell, W. G.; Clinical Pharmacokinetics 1998, 34, 347.

9. Liu, M.; Lin, T.; Sartorelli, A. C.; J. Med. Chem. 1992, 35, 3672.

10. Sartorelli, A. C.; Agrawal, K. C.; Tshtsoglu, A. S.; Moore, E. C.; $A d v$. Enzyme Regul. 1977, 15, 117.

11. Feun, L.; Modiano, M.; Lee, K.; Mao, J.; Marini, A.; Savaraj, N.; Plezia, P.; Almassian, B.; Colacino, E.; Fischer, J.; Macdonald, S.; Cancer Chemother. Pharmacol. 2002, 50, 223.

12. Kasuga, N. C.; Sekino, K.; Ishikawa, M.; Honda, A.; Yokoyama, M.; Nakano, S.; Shimada, N.; Koumo, C.; Nomiya, K.; J. Inorg. Biochem 2003, 96, 298.

13. Teitz, Y.; Ronen, D.; Vansover, A.; Stematsky, T.; Riggs, J. L.; Antiviral Res. 1994, 24, 305

14. Bharti, N.; Husain, K.; Garza, M. T. G.; Vega, D. E. C.; Garza, J. C.; Cardenas, B. D. M.; Naqvi, F.; Bioorg. Med. Chem. Lett. 2002, 12, 3475.

15. Karah, N.; Eur. J. Med. Chem. 2002, 37, 909.

16. Panico, R.; Powell, W. H.; Richer, J. C.; eds.; IUPAC - Nomenclature of organic compounds; Blackwell: London, 1993.

17. Casas, J. S.; Tasende, M. S. G.; Sordo, J.; Coord. Chem. Rev. 2000, 209, 197.

18. Hang, H. C.; Bertozzi, C. R.; Acc. Chem. Res. 2001, 34, 727.

19. Antonini, I.; Claudi, F.; Cristalli, G.; Franchetti, P.; Grifantini, M.; Martelli, S.; J. Med. Chem. 1981, 24, 1181.

20. Du, X.; Gou, C.; Hansell, E.; Doyle, P. S.; Caffrey, C. R.; Holler, T. P.; Mckerrow, J. H.; Cohen, F. E.; J. Med. Chem. 2002, 45, 2695

21. Chattopadhyay, D.; Mazumdar, S. K.; Banerjee, T.; Sheldrick, W. S.; Acta Crystallogr, Sect. C: Cryst. Struct. Commun. 1989, 45, 314.

22. Palenik, G. J.; Rendle, D. F.; Carter, W. S.; Acta Crystallogr., Sect. B: Struct. Sci. 1974, 30, 2390

23. Allen, F. H.; Kennard, O.; Taylor, R.; Acc. Chem. Res. 1983, 16, 146.

24. Tarasconi, P.; Capacchi, S.; Pelosi, G.; Cornia, M.; Albertini, R.; Bonati, A.; Dall'aglio, P. P.; Lunghi, P.; Pinelli, S.; Bioorg. Med. Chem. 2000, 8, 157.

25. Jouad, E. M.; Riou, A.; Allain, M.; Khan, M. A.; Bouet, G. M.; Polyhedron 2001, 20, 67

26. Ferrari, M. B.; Bonardi, A.; Fava, G. G.; Pelizzi, C.; Tarasconi, P.; Inorg Chim. Acta 1994, 223, 77 .

27. Bharti, N.; Shailendra; Sharma, S.; Naqvi, F.; Azam, A.; Bioorg. Med. Chem. 2003, 11, 2923

28. Antonini, I.; Claudi, F.; Franchetti, P.; Grifantini, M.; Marteli, S.; J. Med. Chem. 1977, 20, 447.

29. Galabov, B.; Ilieva, S.; Hadjieva, B.; Dinchova, E.; J. Phys. Chem. A 2003, 107,5854

30. Lauvergnat, D.; Hiberty, P. C.; J. Am. Chem. Soc. 1997, 119, 9478.

31. Vassilev, N. G.; Dimitrov, V. S.; J. Mol. Struct. 2003, 654, 27.

32. Crews, P.; Rodríguez, J.; Jaspars, M.; Organic structure analysis, $1^{\text {th }}$ ed., Oxford University Press, Inc: New York, 1998.

33. Saha, N. C.; Saha, A.; Butcher, R. J.; Chaudhuri, S.; Saha, N.; Inorg. Chim Acta 2002, 339, 348.

34. Shailendra; Bharti, N.; Naqvi, F.; Azam, A.; Bioorg. Med. Chem. Lett. 2003, 13,689 .

35. Holla, B. S.; Malini, K. V.; Rao, B. S.; Sarojini, B. K.; Kumari, N. S.; Eur. J. Med. Chem. 2003, 38, 313.

36. Gupta, R. P.; Narayana, N. L.; Pharmaceutica Acta Helvetiae 1997, 72, 43.

37. Sarodnick, G.; Heydenreich, M.; Linker, T.; Kleinpeter, E.; Tetrahedron 2003, 59, 6311.

38. Somogly, L.; Tetrahedron 1991, 47, 9305.

39. Weinstock, L. T.; Cheng, C. C.; J. Med. Chem. 1979, 22, 594

40. Benbrook, D. M.; Madler, M. M.; Spruce, L. W.; Birckbichler, P. J.; Nelson, E. C.; Subramanian, S.; Weerasekare, G. M.; Gale, J. B.; Patterson, M. K.; Wang, B.; Wang, W.; Lu, S.; Rowland, T. C.; Disevestro, P.; Lindamood, C.; Hill, D. L.; Berlin, D.; J. Med. Chem. 1997, 40, 3567.

41. Rodriguez, E. C.; Marcaurelle, L. A.; Bertozzi, C. R.; J. Org. Chem. 1998, 63,7134 .
42. Costa, P.; Pilli, R.; Pinheiro, S.; Vasconcellos, M.; Substâncias carboniladas e seus derivados, $1^{\mathrm{a}}$ ed., Bookman: Porto Alegre/MG, 2003.

43. Solomons, G.; Fryhle, C.; Química orgânica, $7^{\mathrm{a}}$ ed., LTC - Livros técnicos científicos Ed. S. A: Rio de Janeiro/RJ, 2002, vol. 2.

44. Waugh, K. M.; Berlin, K. D.; Ford, W. T.; Holt, E. M.; Carrol, J. P.; J. Med. Chem. 1985, 28, 116.

45. Chiyanzu, I.; Hansell, E.; Gut, J.; Rosenthal, P. J.; Mckerrow, J. H.; Chibale, K.; Bioorg. Med. Chem. Lett. 2003, 13, 3527.

46. Afrasiabi, Z.; Sinn, E.; Padhye, S.; Dutta, S.; Padhye, S.; Newton, C.; Anson, C. E.; Powell, A. K.; J. Inorg. Biochem. 2003, 95, 306.

47. Lemke, T. L.; Shek, T. W.; Cates, L. A.; Smith, L. K.; J. Med. Chem. 1977, 20, 1351.

48. Ota, A. T.; Temperini, M. L. A.; Arêas, E. P. G.; Loos, M.; J. Mol. Struct. (Theochem) 1998, 451, 269

49. Temperini, M. L. A.; Santos, M. R.; Monteiro, V. R. P.; Spectrochim. Acta Part A 1995, 51, 1517.

50. Karabatsos, G. J.; Vane, F. M.; Taller, R. A.; Hsi, N.; J. Am. Chem. Soc. 1964, 86, 3351

51. O'sullivan, D. G.; Sadler, P. W.; Webley, C.; Chemotherapia 1963, 7, 17.

52. Ashton, W. T.; Cantone, C. L.; Chang, L. L.; Hutchins, S. M.; Strelitz, R. A.; Maccoss, M.; Chang, R. S. L.; Lotti, V. J.; Faust, K. A.; Chen, T.; Bunting, P.; Schorn, T. W.; Kivlighn, S. D.; Siegl, P. K. S.; J. Med. Chem. 1993, 36, 591

53. Kaneko, T.; Willner, D.; Monkovic, I.; Knipe, J. O.; Braslawsky, G. R.; Greenfield, R. S.; Vyas, D. M.; Bioconjugate Chem. 1991, 2, 133.

54. Easmon, J.; Heinisch, G.; Holzer, W.; Rosenwirth, B.; J. Med. Chem. 1992 $35,3288$.

55. Klayman, D. L.; Lin, A. J.; Mccall, J. W.; Wang, S. Y.; Townson, S.; Grögl, M.; Kinnamon, K. E.; J. Med. Chem. 1991, 34, 1422.

56. Duffy, K. J.; Shaw, A. N.; Delorme, E.; Dillon, S. B.; Erickson-miller, C.; Giampa, L.; Huang, Y.; Keenan, R. M.; Lamb, P.; Liu, N.; Miller, S. G.; Price, A. T.; Rosen, J.; Smith, H.; Wiggall, K. J.; Zhang, L.; Luengo, J. I.; J. Med. Chem. 2002, 45, 3573

57. Gürsoy, A.; Terzioglu, N.; Ötuk, G.; Eur. J. Med. Chem. 1997, 32, 753

58. Papastaikoudi, T. S.; Tsotinis, A.; Raptopoulou, C.; Sambani, C.; Thomou, H.; Eur. J. Med. Chem. 1995, 30, 107.

59. Demilo, A. B.; Redfern, R. E.; Borkovec, A. B.; J. Agric. Food Chem. 1983 31,713

60. Klayman, D. L.; Scovill, J. P.; Bartosevich, J. F.; Mason, C. J.; J. Med. Chem. 1979, 22, 1367.

61. Pandeya, S. N.; Sriram, D.; Nath, G.; Declercq, E.; Eur. J. Med. Chem. 1999, 9,25 .

62. Chauvière, G.; Bouteille, B.; Enanga, B.; Albuquerque, C.; Croft, S. L.; Dumas, M.; Périè, J.; J. Med. Chem. 2003, 46, 427.

63. Kubota, S.; Ueda, Y.; Fujikane, K.; Toyooka, K.; Shibuya, M.; J. Org. Chem. 1980, 45, 1473.

64. Ivanchtchenko, A. V.; Il'yin, A. P.; Kobak, V. V.; Zolotarev, D. A.; Boksha, L. V.; Trifilenkov, A. S.; Ugoleva, D. M.; J. Comb. Chem. 2002, 4, 419.

65. Bobek, M.; Glowka, M.; Parthasarathy, R.; J. Org. Chem. 1982, 47, 913.

66. Ral, S. K.; Tiwarl, U. K.; Srivastava, P. K.; J. Chem. Eng. Data 1985, 30 515 .

67. All, M. R.; Singh, R.; Verma, V. K.; J. Chem. Eng. Data 1983, 28, 276.

68. Srivastava, P. K.; Ral, S. K.; J. Chem. Eng. Data 1980, 25, 400

69. Brown, F. C.; Chem. Rev. 1961, 61, 463.

70. Alves, A. J.; Leite, A. C. L.; Santana, D. P.; Beltrão, T. M.; Coelho, M. R. D.; Il Farmaco 1993, 48, 1167.

71. Liu, H. L.; Li, Z.; Anthonsen, T; Molecules 2000, 5, 1055.

72. Küçükgüzzel, S. G.; Oruç, E. E.; Rollas, S.; Sahin, F.; Özbek, A.; Eur. J. Med. Chem. 2002, 37, 197.

73. Reeve, W.; Barron, E. R.; J. Org. Chem. 1975, 40, 1917.

74. Tenório, R. P.; Lima, J. G.; Faria, A. R.; Alves, A. J.; Melo, E. J. T.; Goés, A. J.; Resumos da $27^{a}$ Reunião Anual da Sociedade Brasileira de Química, Salvador, Brasil, 2004.

75. Abbady, M. A.; Hafez, S. H. A.; Kandeel, M. M.; Monem, M. I. A.; Molecules 2003, 8, 622

76. Ullas, G. V.; Chu, C. K.; Ahn, M. K.; Kosugi, Y.; J. Org. Chem. 1988, 53 , 2413.

77. Beraldo, H.; Quim. Nova 2004, 27, 461 .

78. Silva, M. J.; Alves, A. J.; Nascimento, S. C.; Il Farmaco 1998, 53, 241

79. Greenbaum, D. C.; Mackey, Z.; Hansell, E.; Doyle, P.; Gut, J.; Caffrey, C. R.; Lehrman, J.; Rosenthal, P. J.; Mckerrow, J. H.; Chibale, K.; J. Med. Chem. 2004, 47, 3212

80. Walcourt, A.; Loyevsky, M.; Lovejoy, D. B.; Gordeuk, V. R.; Richardson, D. R.; Int. J. Biochem. Cell Biol. 2003, 36, 401.

81. Singh, S.; Bharti, N.; Naqvi, F.; Azam, A.; Eur. J. Med. Chem. 2004, 39, 459

82. Klayman, D. L.; Scovill, J. P.; Bartosevich, J. F.; Bruce, J.; Eur. J. Med. Chem. - Chim. Ther. 1984, 19, 49. 
83. Casero, R. A.; Klayman, D. L.; Childs, G. E.; Scovill, J. P.; desjardins, R E.; Antimicrob. Agents Chemother. 1980, 18, 317.

84. Dodd, R. H.; Ouannès, C.; Géro, M. R.; Potier, P.; J. Med. Chem. 1989 32,1272 .
85. Casas, J. S.; Argüelles-rodríguez, M. C.; Russo, U.; Sánchez, A.; Sordo, J.; López-Vázquez, A.; Pinelli, S.; Lunghi, P.; Bonati, A.; Albertini, R.; J. Inorg. Biochem. 1998, 69, 283.

86. Genova, P.; Varadinova, T.; Matesanz, A. I.; ,Marinova, D.; Souza, P.; Toxicol. Appl. Pharmacol. 2004, 197, 107.

87. Niu, C.; Li, J.; Doyle, T. W.; Chen, S.; Tetrahedron 1998, 54, 6311. 